\title{
The influence of different geometrical dimensions of convectors on the heat transfer from panel radiators
}

\author{
Tamer Calisir $^{1}$ (D) . Senol Baskaya ${ }^{1}$ (D)
}

Received: 29 January 2020 / Accepted: 27 January 2021 / Published online: 6 February 2021

(c) The Author(s) 2021 OPEN

\begin{abstract}
Increase in total heat output of panel radiators could play an important role in domestic energy saving, where convectors (convection fins) play a key role. Hence, it is important to obtain the best possible design of convectors, in order to increase the heat output of panel radiators. In this sense, a numerical study has been performed to show the effects of different geometrical dimensions of convectors on the heat transfer used in domestic panel radiators, to obtain the highest possible total heat output. Firstly, simulation data were verified by analytical results, and afterwards, parametric studies were performed for a single convector mounted on a constant temperature wall, and the natural convective heat transfer has been modelled. The effects of convector height, convector sheet thickness, convector trapezoidal height, distance between opposing convectors, convector tip width, vertical location of convector and cut-off ratio have been considered. The results showed that the heat transfer increases with the increase in convector thickness and height. However, the consumed sheet metal material amount increases as well. From a manufacturing point of view, this should be considered at the same time. On the other hand, with the increase in trapezoidal height, the heat transfer increases, and above a certain value the heat transfer decreases. The heat transfer increases with the distance of opposing convectors and becomes almost constant above a certain value. The results of the present study could guide in the change of the internal design of panel radiators with convectors, in order to increase the heat transfer and reduce material costs.
\end{abstract}

\section{Keywords Panel radiator $\cdot$ Heat transfer $\cdot$ Convector $\cdot$ Natural convection $\cdot$ CFD}

\section{List of symbols}

$b \quad$ Convector tip width $(\mathrm{mm})$

$B \quad$ Base length of convector ( $\mathrm{mm})$

C Cut-off ratio of convector (\%)

$c_{p} \quad$ Specific heat $(\mathrm{J} / \mathrm{kg} \mathrm{K})$

$d \quad$ Distance between opposing convectors $(\mathrm{mm})$

$D \quad$ Distance between convectors $(\mathrm{mm})$

$f \quad$ Vertical convector location $(\mathrm{mm})$

g Gravity $\left(\mathrm{m} / \mathrm{s}^{2}\right)$

Gr Grashof number

$\left(\mathrm{Gr}=g \times \beta \times\left(T_{\mathrm{w}}-T_{\mathrm{a}}\right) \times W^{3} / v^{2}\right)$

$H \quad$ Convector height $(\mathrm{mm})$

$k \quad$ Thermal conductivity coefficient $(\mathrm{W} / \mathrm{m} \mathrm{K})$

$L \quad$ Convector trapezoidal height $(\mathrm{mm})$

$\mathrm{Nu} \quad$ Average Nusselt number (-)

$\begin{array}{ll}p & \text { Pressure }(\mathrm{Pa}) \\ \mathrm{Pr} & \text { Prandtl number }\left(\mathrm{Pr}=v / \alpha=\mu \cdot c_{p} / \mathrm{k}\right) \\ q & \text { Heat transfer per unit length }(\mathrm{W} / \mathrm{m}) \\ \mathrm{Ra} & \text { Rayleigh number }(-) \\ \mathrm{S} & \text { Channel height }(\mathrm{mm}) \\ t & \text { Convector sheet thickness }(\mathrm{mm}) \\ T & \text { Temperature }\left({ }^{\circ} \mathrm{C}\right) \\ T_{\mathrm{a}} & \text { Air temperature }\left({ }^{\circ} \mathrm{C}\right) \\ T_{\mathrm{cf}} & \text { Convection fin surface temperature }\left({ }^{\circ} \mathrm{C}\right) \\ T_{\mathrm{f}} & \text { Film temperature }\left({ }^{\circ} \mathrm{C}\right) \\ T_{\mathrm{w}} & \text { Wall temperature }\left({ }^{\circ} \mathrm{C}\right) \\ u, v, w & \text { Velocity components }(\mathrm{m} / \mathrm{s}) \\ W & \text { Panel total width }(\mathrm{mm}) \\ x, y, z & \text { Coordinates }(-)\end{array}$

Pressure $(\mathrm{Pa})$

$q \quad$ Heat transfer per unit length $(\mathrm{W} / \mathrm{m})$

Ra Rayleigh number (-)

$S \quad$ Channel height $(\mathrm{mm})$

$t \quad$ Convector sheet thickness $(\mathrm{mm})$

$T \quad$ Temperature $\left({ }^{\circ} \mathrm{C}\right)$

$T_{\text {a }} \quad$ Air temperature $\left({ }^{\circ} \mathrm{C}\right)$

$T_{\text {cf }} \quad$ Convection fin surface temperature $\left({ }^{\circ} \mathrm{C}\right)$

Film temperature $\left({ }^{\circ} \mathrm{C}\right)$

$T_{\mathrm{w}} \quad$ Wall temperature $\left({ }^{\circ} \mathrm{C}\right)$

$u, v, w$ Velocity components $(\mathrm{m} / \mathrm{s})$

$x, y, z \quad$ Coordinates (-)

Tamer Calisir, tamercalisir@gazi.edu.tr| 'Department of Mechanical Engineering, Gazi University, Ankara, Turkey. 


\section{Greek symbols}

a Thermal diffusivity $\left(\mathrm{m}^{2} / \mathrm{s}\right)$

$\beta \quad$ Thermal expansion coefficient $\left(\beta=1 / T_{\mathrm{f}}-1 / K\right)$

$\mu \quad$ Dynamic viscosity $(\mathrm{kg} / \mathrm{m} \mathrm{s})$

$v \quad$ Kinematic viscosity $\left(\mathrm{m}^{2} / \mathrm{s}\right)$

$\rho \quad$ Density $\left(\mathrm{kg} / \mathrm{m}^{3}\right.$

\section{Subscripts and superscripts}

a Air

cf Convection fin

f Film

w Wall

\section{Introduction}

Buildings are one of the greatest energy consumers worldwide, with a share of approximately $45 \%$ to the total energy consumption [1]. Heating of buildings contributes to this share at a high rate. Hence, the demand for heating systems with higher efficiency and heat output increases day by day. One of the most common used heating devices are panel radiators equipped with convection fins (convectors) $[2,3]$. Therefore, the increase of the heat output supplied by these heating devices is of importance.

The design of convectors used in panel radiators has an important impact in the total heat output. Therefore, to obtain highest possible heat output of panel radiators, various geometrical dimensions of convectors play an inevitable role. For this reason, a major focus was directed on the internal design of panel radiators, to make them more thermally efficient.

The principle parts of panel radiators as well as occurring heat transfer mechanisms are shown in Fig. 1. The main part of the heat transfer from panel radiators, has been observed by the same group of authors, to be by natural convection, whereas the rate of radiation is around $26 \%$, for an inlet/outlet temperature of $75 / 65^{\circ} \mathrm{C}$ [4]. The hot circulation water inside the channels transfers its heat to colder air inside the room, which passes through the panels and convectors. Temperature difference between the radiator surfaces and environmental air induces buoyancy forces, which are the main driving forces. In order to increase the convective heat transfer, most panel radiators are equipped with convection fins (convectors) [5].

There are few studies on the convective heat transfer between the panel and convectors of radiators. Although there are many studies conducted on natural convective heat transfer between parallel plates and channels, the subject of the effect of convection fins (convectors) on heat transfer has not been investigated in depth. The heat output of convectors mounted between panels of ventilation radiators has been investigated numerically by Myhren and Holmberg [5, 6]. The performance of ventilation radiators and comparison with traditional radiators has been done by Myhren and Holmberg [7]. An experimental study was performed by Mundt et al. [8] to show the performance of vent convectors, by airflow and pressure drop characteristics. High emissivity sheets have been used by Beck et al. [3] between the panels of a radiator
Fig. 1 Main parts of panel radiators and occurring heat transfer mechanisms

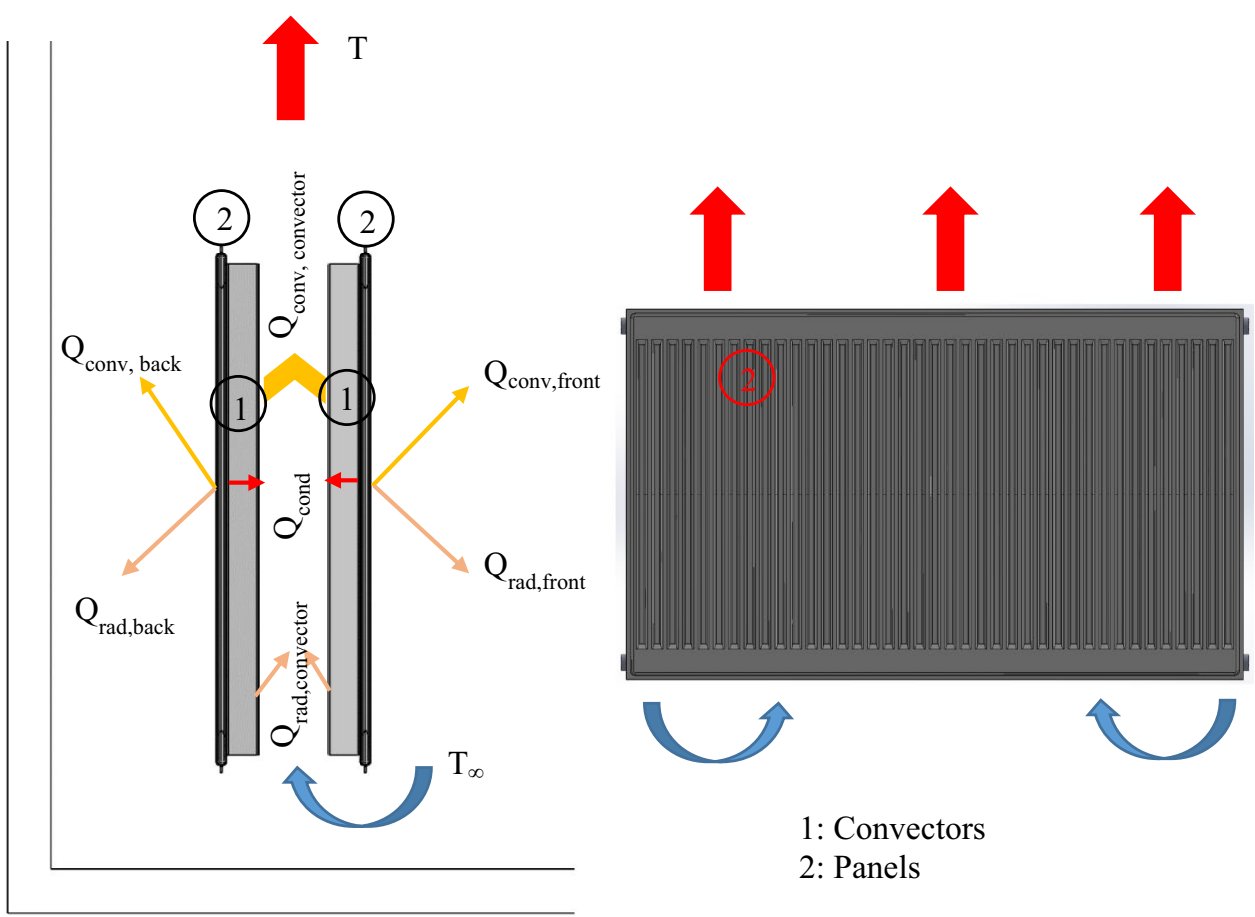


in order to show the effect on the heat transfer of panel radiators. An experimental and numerical study was performed by Yedikardes and Teke [9] to show the effect of louvres made up on panel radiator surfaces. Arslanturk [10] and Arslanturk and Ozguc [2] have built analytical models and investigated different parameters in the optimization study for panel radiators to enhance heat transfer. An experimental study was done by Bagheri et al. [11] to evaluate the thermal performance of convectors and fin-clips used on hydronic baseboard heaters. A numerical examination was presented by Tran and Wang [12] to optimize the thermal performance of flat-tube radiators by investigating the effect of the type, pitch, thickness and louver angle of fins. Ploskic et al. [13] explored the airflow and convector plate design on the thermal performance of ventilation radiators. Gheibi and Rahmati [14] used waving fins and changed the cross section of the fluid of baseboard radiators to enhance the thermal efficiency of skirting baseboard heaters. Water flow arrangement was investigated by Prek and Krese [15] on the heat output of panel radiators.

The review presented above shows that there are some studies that can be realized to increase the heat transfer from convectors used in radiators. However, the studies about the effect of convectors on the heat transfer of panel radiators are few. In addition, almost none of them has concentrated on the different dimensions of convectors used inside the panels of radiators. Although some studies have been performed about the effect of convectors, few of these studies focused on the heat transfer, flow and temperature distribution from convection fins under different geometrical designs. Hence, in the present study, simulations have been performed for different convector heights $(H)$, convector sheet thicknesses $(t)$, convector trapezoidal heights $(L)$, distances between opposing convectors $(d)$, convector tip widths $(b)$, vertical locations of convectors $(f)$ and cut-off ratios $(c)$ under constant surface temperature conditions, to show their effects on the heat transfer per unit length of radiator.

The approach and findings could be beneficial and could provide guidance for panel radiator manufacturers, where the results contain a wide range of parameters of convectors, in order to obtain the highest heat output from panel radiators.

In the present study, the main objective was to investigate the effects of different geometrical dimensions of convectors used in radiators, in order to achieve the highest possible heat output of panel radiators without compromising functionality and manufacturability. Special attention was given to the main geometrical parameters of convectors placed between the radiator panels, in order to find out whether the heat output of panel radiators could be increased. The findings could guide in the design of new type of panel radiators. Therefore, in the present study, the heat transfer occurring between the panels and around the convectors of radiators has been investigated numerically for different geometrical parameters of convectors, to observe their effects on the heat transfer, which will be new for the relevant literature. The study has been performed for only one convector, and it was aimed to obtain the most effective parameters in order to increase the heat transfer and accordingly the heat output of panel radiators.

\section{Method}

The PHOENICS CFD code has been employed in the present study. A whole radiator geometry in 3-D and the upper view of that radiator is presented in Fig. 2a. The computational domain and boundary conditions (Fig. 2b) and the investigated parameters of the convectors are shown (Fig. 2c). Two opposed convectors have been modelled and were placed on a constant temperature surface of $T_{\mathrm{w}}=60^{\circ} \mathrm{C}$ along $x=0$ and $x=W$ (Fig. 2c). These are locations where the convectors have been mounted. The temperature was implemented according to usual habits of end-users (Fig. 2b). The computational domain consists of these convectors and air around the convectors. Conduction heat transfer along the convection fins has also been modelled, and the height of the fins $(H)$ were in general mounted at the mid-section of the channel. Natural convective flow has been modelled inside the channel. Density differences occur due to the temperature gradients, which causes buoyancy forces. At $z=0 \mathrm{~mm}$ fluid entrance occurs and leaves the channel at $z=600 \mathrm{~mm}$. The computational domain was built as shown in Fig. $2 \mathrm{c}$. Figure $2 \mathrm{c}$ shows the height of the computational domain, which has been modelled as $S=600 \mathrm{~mm}$ along the $z$-axis. The lower $(z=0 \mathrm{~mm})$ and upper $(z=600 \mathrm{~mm})$ parts of the channel were modelled as outlets (Fig. 2b). Air with a temperature of $20^{\circ} \mathrm{C}$ was used as the working fluid. The side surfaces $(y=0 \mathrm{~mm}$ and $y=p)$ were specified as symmetry boundary conditions (Fig. 2b).

The domain has been modelled as a quarter part as shown in Fig. 2c, with the aim to decrease computational time. The cut section has been shown as $\mathrm{C}-\mathrm{C}$ in Fig. 2c. Preliminary results showed that the findings are in agreement with the results of the whole convector [16]; hence, the study was continued with a quarter part of the model. In Fig. 2c, the dimensions of the computational domain and convectors are shown in the $x-y$ plane. $B$ shows the dimension which is in contact with the heated wall, $D$ shows the distance between convectors, $d$ is the distance between opposing convectors, $t$ is the convector sheet thickness, $b$ is the tip width of the 
Fig. 2 Computational domain and boundary conditions a PCCP type panel radiator, $\mathbf{b}$ implemented boundary conditions, c investigated convector dimensions

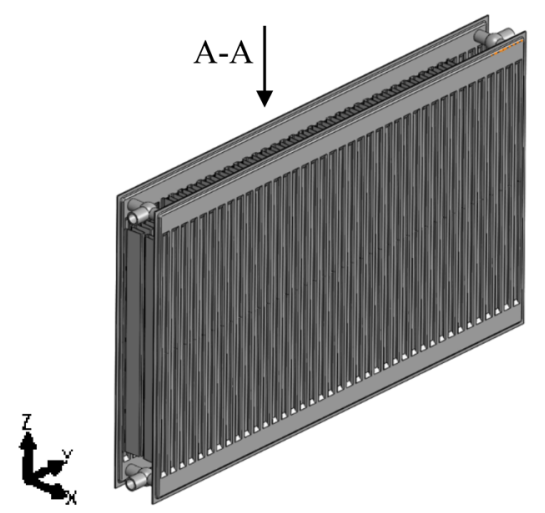

(a)
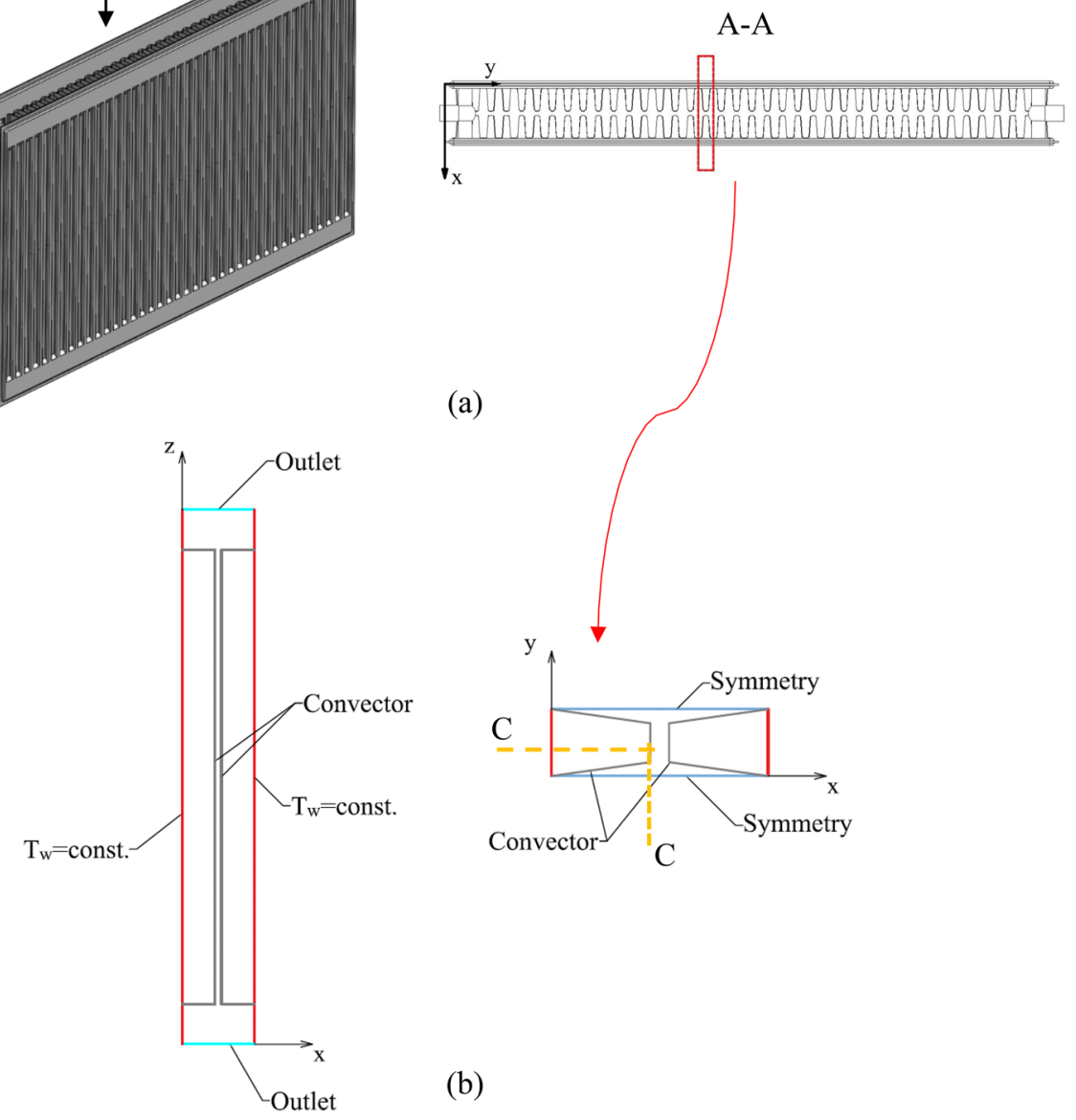

(b)
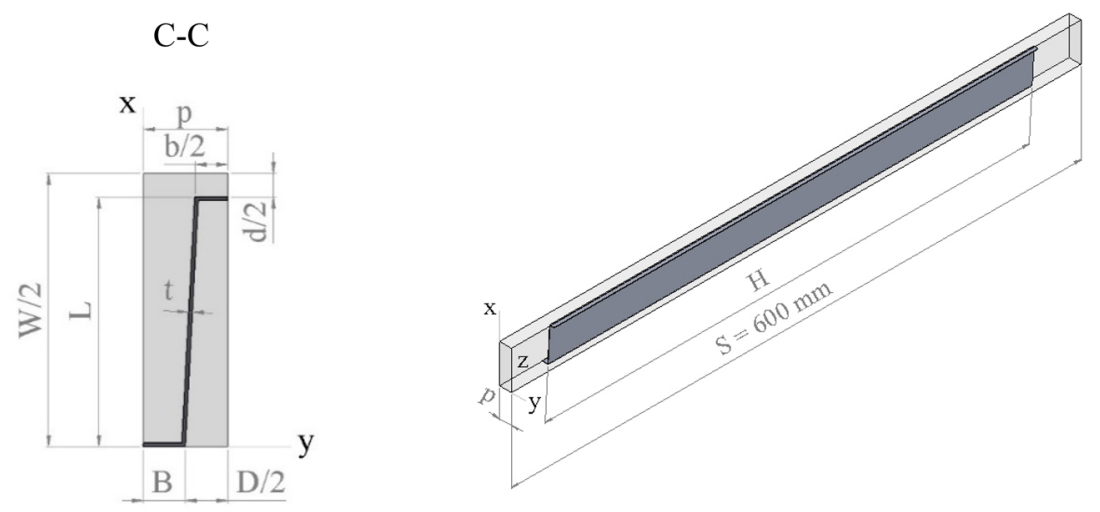

(c)

convector, $L$ is the trapezoidal height of the convector, $W$ and $p$ are the width and depth of the computational domain in the $x$ and $y$ directions, respectively.

Table 1 represents the dimensions and parameters under investigation. The top view of the radiator and a section view, which shows the front of the radiator, are shown in Table 1. The numerical study was performed for the parameters given in the table. Steel was used as convector material within the simulations. The properties of the convector material are shown in Table 2.

\subsection{Governing equations and data reduction}

The governing equations were converted to discretized equations by using the control volume approach, and discretized equations were solved iteratively. The numerical 
Table 1 Description of convector configurations and investigated parameters
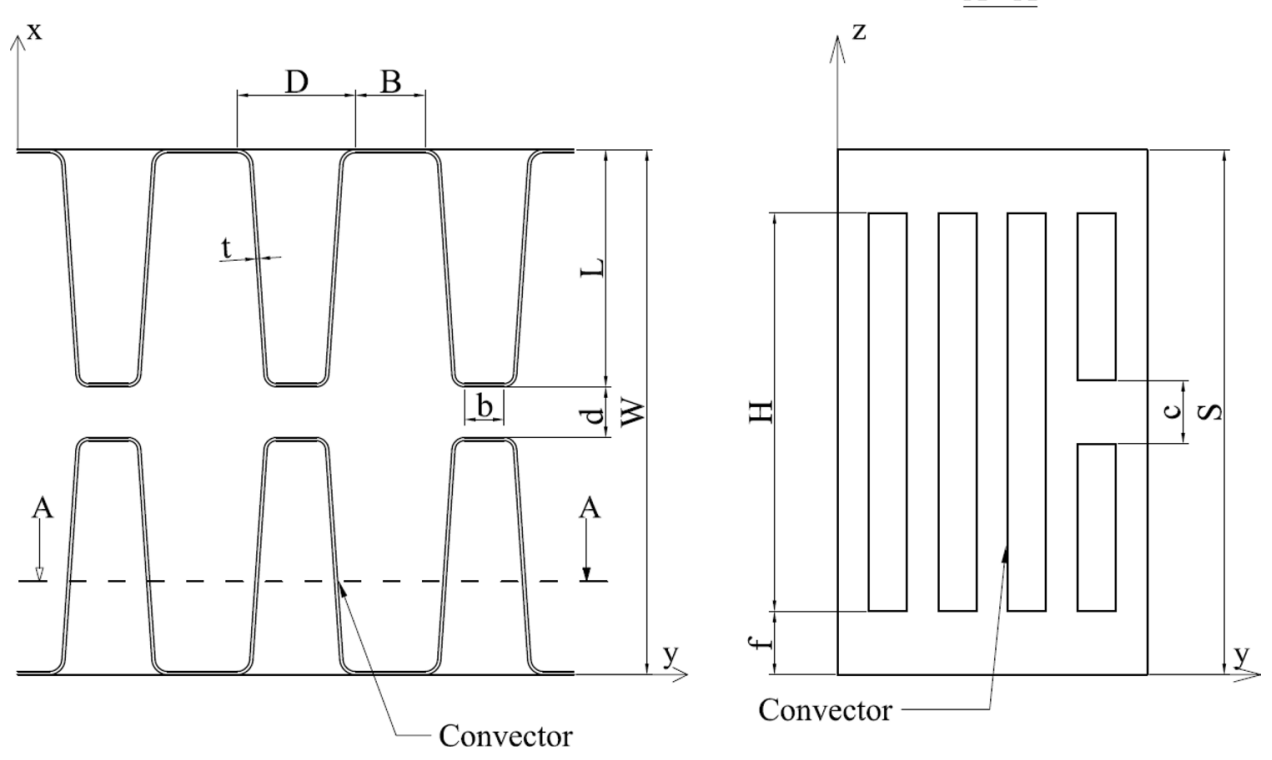

\begin{tabular}{llr}
\hline Parameter & Parameter description & Investigation range \\
\hline$H$ & Convector height & $450-600 \mathrm{~mm}$ \\
$t$ & Convector sheet thickness & $0.25-0.60 \mathrm{~mm}$ \\
$L$ & Convector trapezoidal height & $25-80 \mathrm{~mm}$ \\
$d$ & Distance between opposing convectors & $0-12 \mathrm{~mm}$ \\
$b$ & Convector tip width & $0-12 \mathrm{~mm}$ \\
$f$ & Vertical location of convector & $0-90 \mathrm{~mm}$ \\
$c$ & Cut-off ratio & $0-100 \%$ \\
\hline
\end{tabular}

Table 2 Properties of steel used as convector material

\begin{tabular}{ll}
\hline Property & Set value \\
\hline$\rho\left(\mathrm{kg} / \mathrm{m}^{3}\right)$ & 7850 \\
$k(\mathrm{~W} / \mathrm{m} \mathrm{K})$ & 19.9 \\
$c_{p}(\mathrm{~J} / \mathrm{kg} \mathrm{K})$ & 450 \\
\hline
\end{tabular}

study was conducted for steady-state conditions in Cartesian coordinates. A 3-D model was considered, and the continuity, momentum and energy equations have been solved for laminar incompressible flow with no viscous dissipation conditions. The SIMPLEST (SIMPLEShorTened) algorithm has been employed to deal with pressure-velocity coupling. The convective-diffusive transport term has been discretized by using the hybrid scheme. The iterations were continued until the residuals of every variable became less than $10^{-7}$. In addition, the conservation of mass, momentum and energy has been checked.

As mentioned before, although these devices are called radiators the highest share in total amount of heat output occurs by natural convection [4]. The rate of radiation occurring between the panels and convectors has been obtained around 2\% of the total heat output by Calisir [16]. Hence, the effect of radiation heat transfer has been neglected in the present study. The gravitational acceleration was defined in the negative $z$ direction with a value of $9.81 \mathrm{~m} / \mathrm{s}^{2}$.

Due to the limited temperature difference, the flow was modelled as "Boussinesq incompressible" for air to take coupling between energy and momentum equations into account. The governing equations were solved for a 3-dimensional steady state, conjugated heat transfer and laminar incompressible flow of air. The equations used in the simulations are given as follows,

$\frac{\partial u}{\partial x}+\frac{\partial v}{\partial y}+\frac{\partial w}{\partial z}=0$

$u \frac{\partial u}{\partial x}+v \frac{\partial u}{\partial y}+w \frac{\partial u}{\partial z}=-\frac{1}{\rho_{\mathrm{a}}} \frac{\partial p}{\partial x}+v\left[\frac{\partial^{2} u}{\partial x^{2}}+\frac{\partial^{2} u}{\partial y^{2}}+\frac{\partial^{2} u}{\partial z^{2}}\right]$ 


$$
\begin{aligned}
& u \frac{\partial v}{\partial x}+v \frac{\partial v}{\partial y}+w \frac{\partial v}{\partial z}=-\frac{1}{\rho_{\mathrm{a}}} \frac{\partial p}{\partial y}+v\left[\frac{\partial^{2} v}{\partial x^{2}}+\frac{\partial^{2} v}{\partial y^{2}}+\frac{\partial^{2} v}{\partial z^{2}}\right] \\
& u \frac{\partial w}{\partial x}+v \frac{\partial w}{\partial y}+w \frac{\partial w}{\partial z}= \\
& -\frac{1}{\rho_{\mathrm{a}}} \frac{\partial p}{\partial z}+v\left[\frac{\partial^{2} w}{\partial x^{2}}+\frac{\partial^{2} w}{\partial y^{2}}+\frac{\partial^{2} w}{\partial z^{2}}\right] \\
& +g \beta\left(T-T_{a}\right) \\
& u \frac{\partial T}{\partial x}+v \frac{\partial T}{\partial y}+w \frac{\partial T}{\partial z}=\frac{v}{\operatorname{Pr}}\left[\frac{\partial^{2} T}{\partial x^{2}}+\frac{\partial^{2} T}{\partial y^{2}}+\frac{\partial^{2} T}{\partial z^{2}}\right]
\end{aligned}
$$$$
\text { (3) } T_{\mathrm{f}}=\frac{\left(T_{\mathrm{w}}+T_{\mathrm{a}}\right)}{2}
$$

The Rayleigh number has been obtained as follows;

$\mathrm{Ra}=\mathrm{Gr} \times \operatorname{Pr}=\frac{g \times \beta \times\left(T_{\mathrm{w}}-T_{\mathrm{a}}\right) \times W^{3}}{\alpha \times v}$

where Gr shows the Grashof number, $W(\mathrm{~m})$ the distance between the opposite heated plates, $g\left(\mathrm{~m} / \mathrm{s}^{2}\right)$ the gravitational acceleration and $\beta(1 / \mathrm{K})$ the thermal expansion coefficient.

The Grashof number was used in order to observe the effect of turbulence. It was observed that the Grashof number is lower than $10^{9}$ for all investigated cases, which is the range of transition to turbulence, hence the flow was modelled as laminar [17].

\subsection{Validation of numerical results}

Preliminary simulations have been performed in order to verify the accuracy of the model. These simulations were done for a case with the convector dimensions of $t=0.37 \mathrm{~mm}, D=12.6 \mathrm{~mm}, B=6.2 \mathrm{~mm}, L=37 \mathrm{~mm}$, $H=510 \mathrm{~mm}, b=9.70 \mathrm{~mm}, d=7 \mathrm{~mm}$. Firstly, an independency check for the iteration number has been performed, and an iteration number of 10,000 was chosen. Afterwards, an independency check for the mesh was performed, and the mesh numbers used with the corresponding heat transfer results are shown in Table 4 . The results become almost independent for a mesh number of 18-12-78. The

Table 4 Grid independency results

\begin{tabular}{lr}
\hline Mesh $(x-y-z)$ & $q(\mathrm{~W} / \mathrm{m})$ \\
\hline $13-8-70$ & 277.85 \\
$18-12-78$ & 1050.04 \\
$23-17-87$ & 1041.77 \\
$27-18-97$ & 1039.57 \\
$30-20-108$ & 1038.23 \\
$33-22-120$ & 1039.76 \\
$35-25-133$ & 1043.22 \\
$39-27-148$ & 1040.66 \\
\hline
\end{tabular}

Table 3 Boundary conditions

\begin{tabular}{rllll}
\hline & $u$ & $v$ & $w$ & $T$ \\
\hline$x=0,0 \leq y \leq p, 0 \leq z \leq S$ & $u=0$ & $v=0$ & $w=0$ & $T_{w}=60^{\circ} C$ \\
$y=W / 2,0 \leq y \leq p, 0 \leq z \leq S$ & $\partial u / \partial x=0$ & $\partial v / \partial x=0$ & $\partial w / \partial x=0$ & $\partial T / \partial x=0$ \\
$y=0,0 \leq x \leq W / 2,0 \leq z \leq S$ & $\partial u / \partial y=0$ & $\partial v / \partial y=0$ & $\partial w / \partial y=0$ & $\partial T / \partial y=0$ \\
$z=p, 0 \leq x \leq W / 2,0 \leq z \leq S$ & $\partial u / \partial y=0$ & $\partial v / \partial y=0$ & $\partial w / \partial y=0$ & $\partial T / \partial y=0$ \\
$z=0,0 \leq x \leq W / 2,0 \leq y \leq p$ & $\partial u / \partial z=0$ & $\partial v / \partial z=0$ & $\partial w / \partial z=0$ & $\partial T / \partial z=0$ \\
$z=S, 0 \leq x \leq W / 2,0 \leq y \leq p$ & $\partial u / \partial z=0$ & $\partial v / \partial z=0$ & $\partial w / \partial z=0$ & $\partial T / \partial z=0$ \\
\hline
\end{tabular}


mesh number used in the whole study was selected as $30-20-108$ in the $x-y-z$ directions, respectively.

The mesh structure used in the presented simulations is shown in Fig. 3. The mesh structure obtained from the mesh independency study is represented in the $x-y$ and $x-z$ planes. The mesh was concentrated in the vicinity of the convection fins and the walls in order to observe the temperature gradients more accurately.

In the field of natural convection, the extended dimensions of the computational domain are important. Hence, the effect of boundary extension on the solution has been obtained, and the results were presented by Calisir [16]. The results showed that extensions have almost no effect on the solution, and therefore, no extension has been implemented on the boundaries.

The problem under investigation has been validated with the empirical equations of Elenbaas [18] and BarCohen and Rohsenow [19], which were obtained for natural convection conditions for symmetrically heated parallel plates for a range of $5.16 \times 10^{5} \leq \mathrm{Ra} \leq 2.32 \times 10^{6}$. This range of Ra numbers corresponds to a temperature difference range between the wall and air of $10-70^{\circ} \mathrm{C}$. The equations of Elenbaas [18] and Bar-Cohen and Rohsenow [19] are given in Eqs. (11) and (12), respectively.

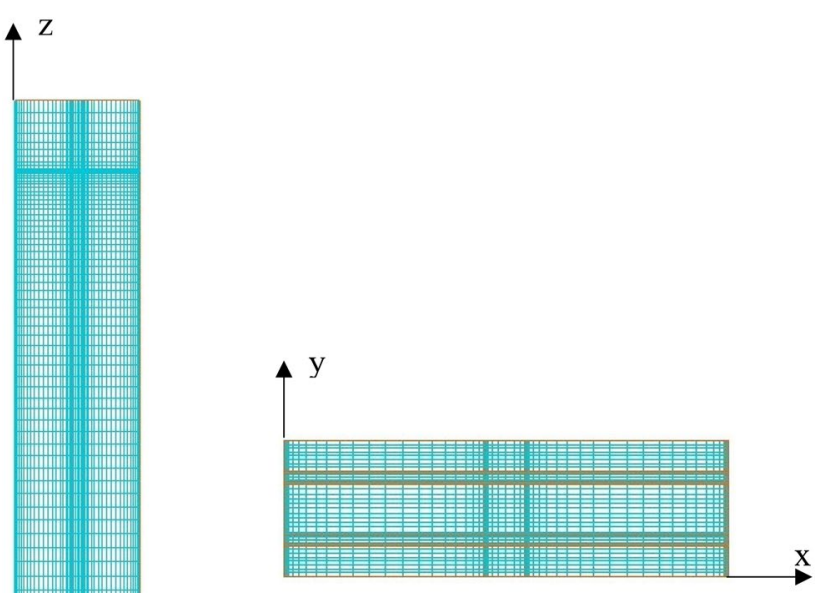

Fig. 3 Mesh structure used in the study
$\mathrm{Nu}=\frac{1}{24} \operatorname{Ra}\left(\frac{W}{S}\right)\left\{1-\exp \left[-\frac{35}{\operatorname{Ra}(W / S)}\right]\right\}^{3 / 4}$

$\mathrm{Nu}=\left[\frac{576}{(\operatorname{Ra} \times W / S)^{2}}+\frac{2.87}{(\operatorname{Ra} \times W / S)^{1 / 2}}\right]^{-1 / 2}$

where Nu shows the average Nusselt number, $W$ the width of the channel and $S$ represents the height of the channel of the computational domain.

The values obtained from the equations given above were compared with present numerical results of the simulations, in order to check for the validity of the numerical results. This comparison was performed for a vertical channel with symmetrically heated walls and without convectors on the walls. The comparison of results and change in the Nu number with respect to the Ra number is given in Fig. 4. The variation in the Ra number occurred with the change in surface temperature, and an ambient air temperature of $20^{\circ} \mathrm{C}$ was used. A good agreement with the theoretical results has been obtained. A maximum deviation of $6.7 \%$ occurred from the theoretical results of BarCohen and Rohsenow [19].

\section{Results and discussions}

The investigation of the effects of different convector dimensions used in panel radiators on the heat transfer was the main goal of the present numerical study. Hence, an intensive simulation study has been performed for convector thickness $(t)$, convector height $(H)$, convector trapezoidal height $(L)$, spacing between two opposing

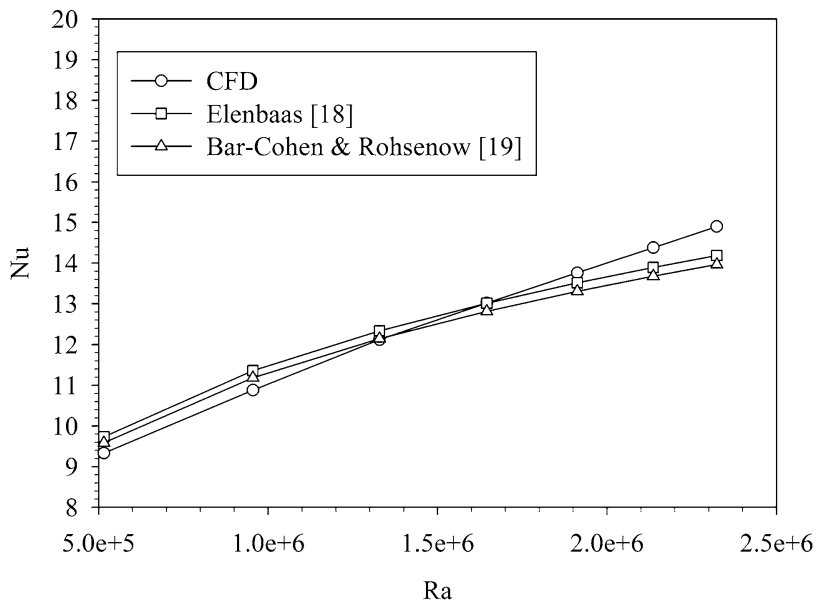

Fig. 4 Verification of CFD results of natural convection heat transfer. Ra number varies with surface temperature in ambient air at $20^{\circ} \mathrm{C}$ 
convectors $(d)$, convector tip width (b), convector vertical location $(f)$ and convector cut-off ratio $(c)$. The obtained results have been normalized to a one-meter length radiator, in order to observe the effect for a whole radiator.

Figure 5 shows the change in heat transfer with convector sheet thickness. In addition, temperature distributions at a horizontal level of $z=300 \mathrm{~mm}$ are shown for thicknesses of $t=0.25 \mathrm{~mm}$ and $t=0.60 \mathrm{~mm}$. The convector height, convector trapezoidal height and distance between opposite convectors were taken constant at $H=510 \mathrm{~mm}, L=37 \mathrm{~mm}$ and $d=7 \mathrm{~mm}$, respectively. A continuous increase in heat transfer occurs with the increase in convector thickness. This is due to the cross section area of the convector, which increases with thickness; hence, the area where conduction heat transfer occurs increases. This fact can be more clearly observed by the temperature distribution, where the temperature values around and in the vicinity of the convectors are higher for a $t=0.60 \mathrm{~mm}$ convector thickness.

In the range of $0.25 \mathrm{~mm} \leq t \leq 0.30 \mathrm{~mm}$, a sudden increase occurs in the heat transfer, and for $t>0.30 \mathrm{~mm}$ the slope of the change in heat transfer decreases. The increase in rate in the range of $0.25 \mathrm{~mm} \leq t \leq 0.30 \mathrm{~mm}$ is almost $10.5 \%$, whereas the increase rate in heat transfer for $0.30 \mathrm{~mm} \leq t \leq 0.60 \mathrm{~mm}$ was calculated as only $9.2 \%$. This increase shows that for a thickness of $t=0.25 \mathrm{~mm}$ the heat transfer could not occur properly, and with the increase to a thickness of $t=0.30 \mathrm{~mm}$ this problem can be solved. This is also observed from the temperature distribution of $t=0.25 \mathrm{~mm}$ at a horizontal level of $300 \mathrm{~mm}$, where the temperature is much lower at the tip of the convection fin, compared to the case of $t=0.60 \mathrm{~mm}$.

The effect of convector height on the heat transfer is shown in Fig. 6a. The convectors are placed at the midsection along the height of the channel. A constant convector thickness of $t=0.50 \mathrm{~mm}$ has been used during the

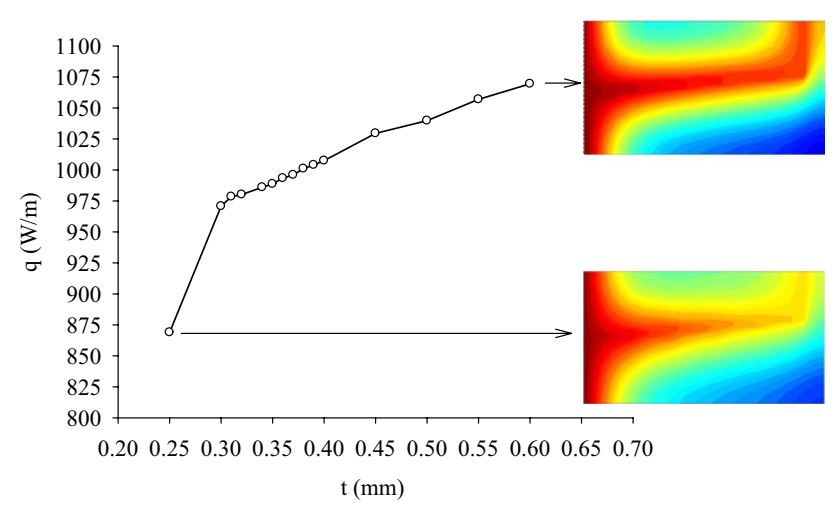

Fig. 5 Heat transfer per meter radiator length as a function of convector thickness and temperature distributions at a horizontal level of $300 \mathrm{~mm}$ study. The trapezoidal height of $L=37 \mathrm{~mm}$ and a distance between opposite convectors of $d=7 \mathrm{~mm}$ were modelled in the investigation of the effect of convector height.

The heat transfer increases almost linearly with the increase in convector height. The increase in the height of the convector increases the contact time of air flowing inside the vertical passage to the convector. In the range of $450 \mathrm{~mm} \leq H \leq 570 \mathrm{~mm}$, an increase in heat transfer at a rate of almost $7.6 \%$ occurs, whereas for $570 \mathrm{~mm} \leq H \leq 600 \mathrm{~mm}$ the increase in rate in heat transfer occurred as $4.7 \%$. Due to the increased heat transfer area, an increase in heat transfer occurs at the lower part of the channel. However, this is not observed for a convector height of $H=450 \mathrm{~mm}$. Figure $6 \mathrm{~b}$ shows that the increase in the height of the convector leads to an increase in temperature, and especially around the convector tip region higher temperatures can be observed. In addition, due to the extended surface at the lower section of the channel for $H=600 \mathrm{~mm}$, the heat transfer is maximized at that region, which in overall has an augmenting effect on the total heat transfer. For $H=600 \mathrm{~mm}$ the convector expands along the whole channel, which hinders the mixing of cold air outside the convectors with the heated air confined inside the convectors, which has an additional increasing effect on heat transfer.

On the whole, the heat transfer can be increased at a rate of around $8 \%$ with the increase of convector height from $H=450 \mathrm{~mm}$ to $H=600 \mathrm{~mm}$. At the same time, the total amount of material was increased by almost 18\% [16].

The trapezoidal height of the convectors is an important parameter, since it is an extension of the convection fin in the direction of the conductive heat transfer. Therefore, the effect of convector trapezoidal height for a range of $25 \mathrm{~mm} \leq L \leq 80 \mathrm{~mm}$ on heat transfer, and temperature distributions along the channel are shown in Fig. 7. As can be seen, the heat transfer increases and reaches a maximum at $L=75 \mathrm{~mm}$. For $L>75 \mathrm{~mm}$, a decrease occurs in the heat transfer. It was also observed that in the range of $25 \mathrm{~mm} \leq L \leq 60 \mathrm{~mm}$, the increase in heat transfer occurs at a rate of $36.8 \%$, whereas the increase rate decreases for $L>60 \mathrm{~mm}$, and in the range of $60 \mathrm{~mm} \leq L \leq 80 \mathrm{~mm}$ the increase rate occurred at a rate of $3.1 \%$. In the design of convection fins, an appropriate length of the fins should be obtained due to the fact that the temperature drops exponentially along the fin [17]. Hence, in the investigated range of trapezoidal heights of the present study, it was observed that this limitation was reached.

This fact can be observed more clearly in Fig. 7b. The temperature distributions along the channel height and at different elevations have been shown in this figure for $L=25 \mathrm{~mm}$ and $L=60 \mathrm{~mm}$. For lower heights, higher temperature values have been obtained along the channel height and at different elevations. However, due to confinement the air velocity decreases, which has a decreasing 
Fig. 6 a Heat transfer per meter radiator length as a function of convector height, b temperature distributions at different horizontal levels of $150 \mathrm{~mm}, 300 \mathrm{~mm}$ and $450 \mathrm{~mm}$

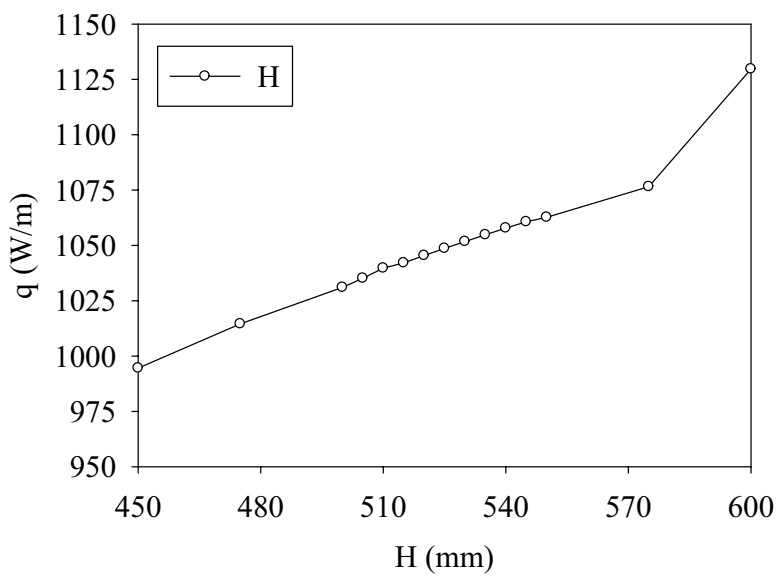

(a)
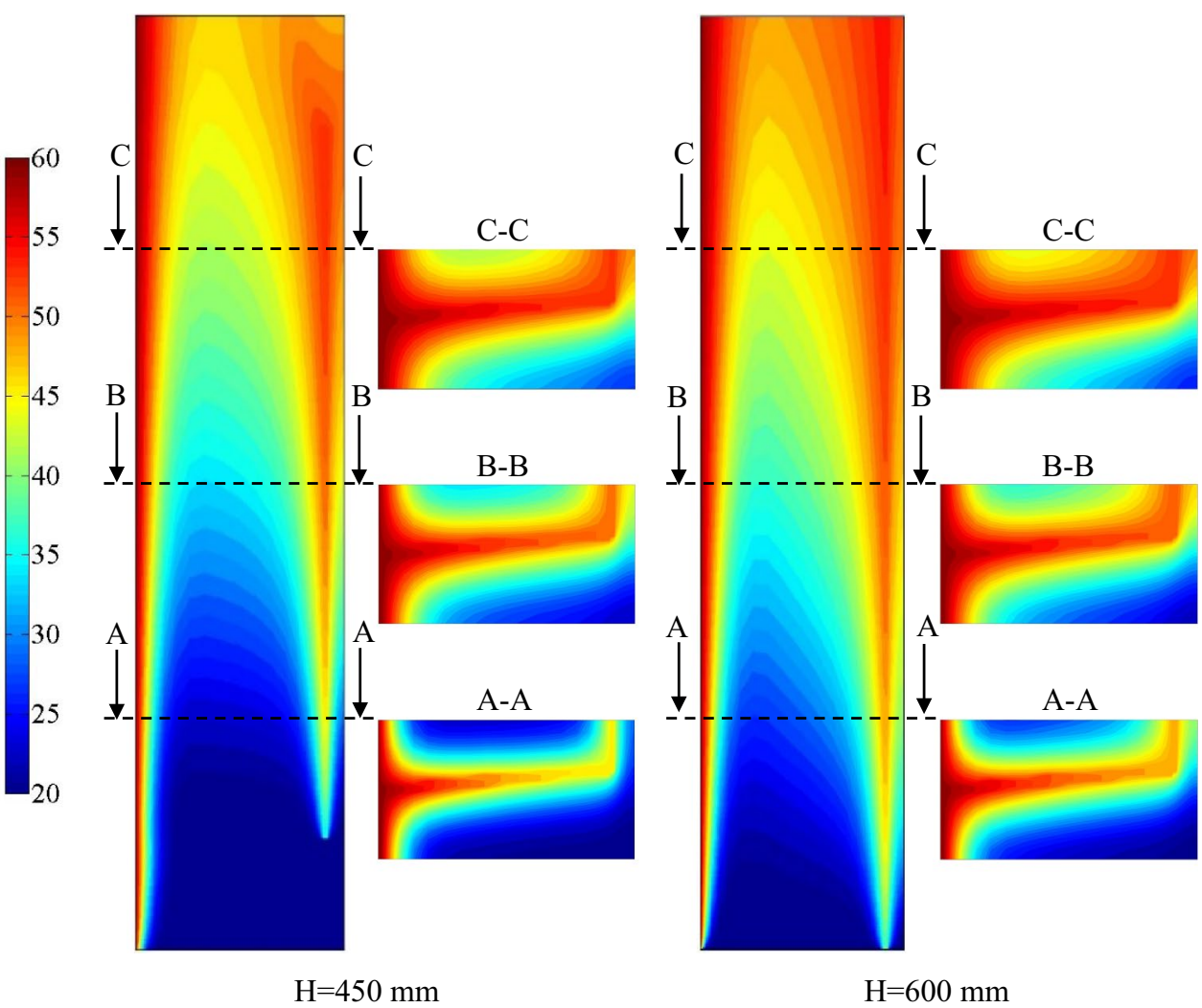

(b) effect on heat transfer. On the other hand, it was observed that with the increase in the trapezoidal height the temperature drops along the fin and lower temperature values are observed at the fin tip region. This shows that for a certain value of trapezoidal height the conduction of heat could not arise properly, which has a decreasing effect on heat transfer.

The effects of distance between two opposing convectors on heat transfer and temperature distribution have been investigated for a range of $0 \mathrm{~mm} \leq d \leq 12 \mathrm{~mm}$. The remaining parameters were held constant as $H=510 \mathrm{~mm}$, $t=0.50 \mathrm{~mm}, L=37 \mathrm{~mm}$, and the convectors were placed at the mid-section along the height of the channel. The effect of the distance between opposite convectors on heat transfer has been shown in Fig. 8a. The heat transfer increases with the increase in distance and becomes almost constant for a distance of $d \geq 6 \mathrm{~mm}$. This occurs due to the high distance between the convectors, which has 
Fig. 7 a Heat transfer per meter radiator length as a function of convector trapezoidal height, $\mathbf{b}$ temperature distributions at different horizontal levels of $150 \mathrm{~mm}$, $300 \mathrm{~mm}$ and $450 \mathrm{~mm}$

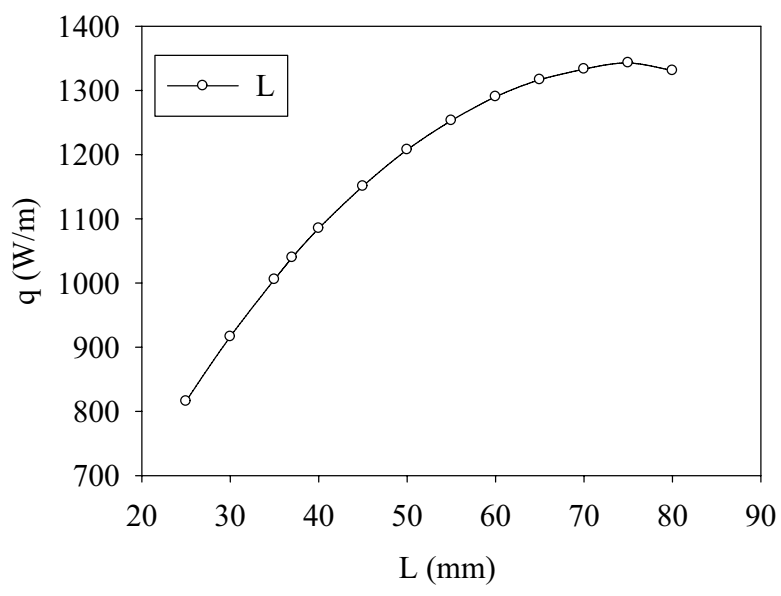

(a)

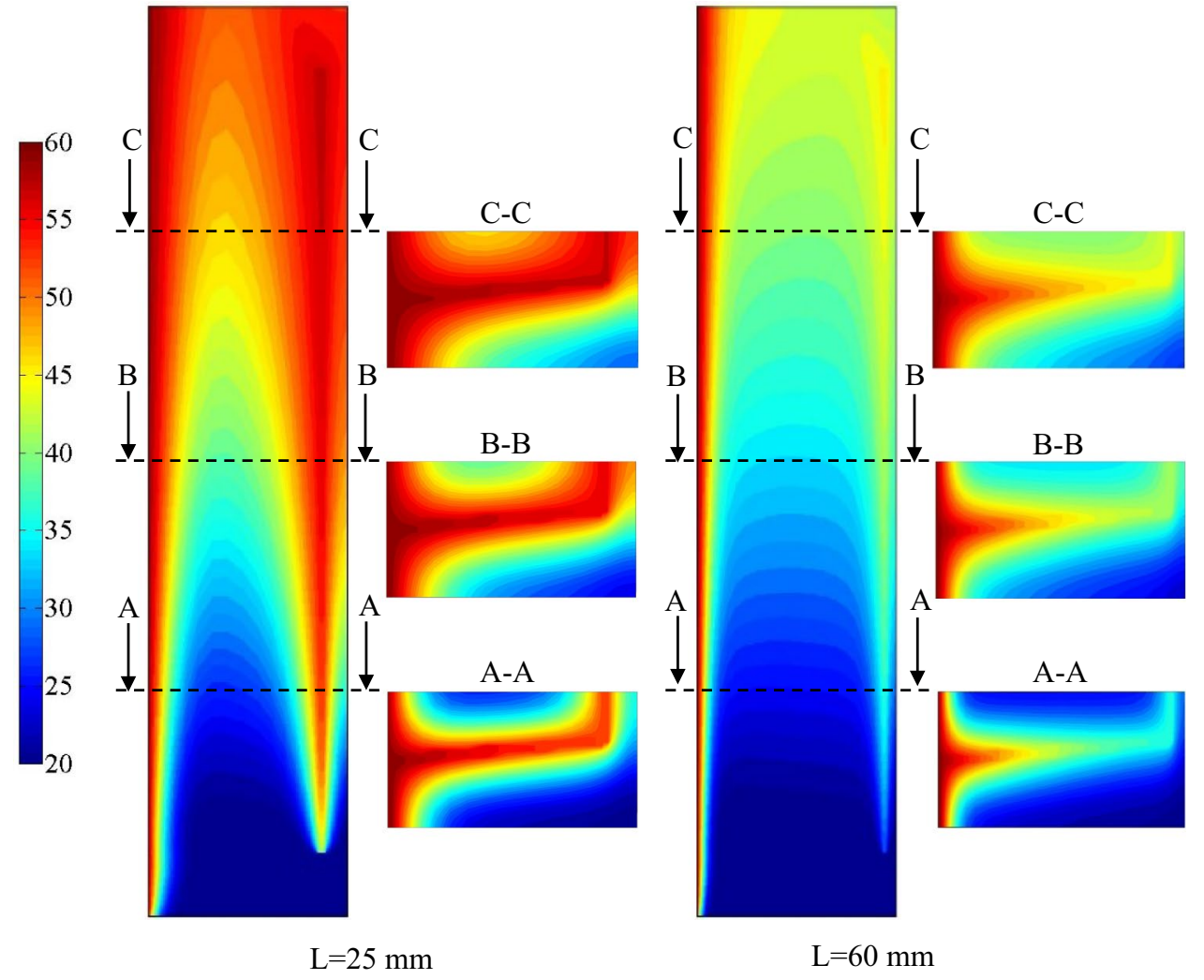

(b) no heating effect on the airflow outside the boundary and in the space between the opposing fins. Hence, the heat transfer is almost not affected after a certain value. However, in the range of $0 \mathrm{~mm} \leq d \leq 6 \mathrm{~mm}$ the heat transfer increases at a rate of approximately $17.9 \%$. The worst case has been obtained for $d=0 \mathrm{~mm}$. This is due to the airflow, which is blocked at the tip region, hence with the decrease in airflow rate the heat transfer decreases.

The obtained temperature distributions are shown in Fig. 8b. It was observed that for a distance of $d=0 \mathrm{~mm}$ high temperatures occur around the tip region of the convectors; however, near the top region (section $\mathrm{C}-\mathrm{C}$ ) a cold region occurs. As can be seen from the velocity distributions, a backflow occurs and cold air entrainment was also observed. This has a decreasing effect on heat transfer; hence, the lowest heat transfer was obtained for $d=0 \mathrm{~mm}$. For a distance of $d=12 \mathrm{~mm}$ a cold region outside the convectors can be seen. This cold region occurs between the two opposite convectors. Hence, after a 
Fig. 8 a Heat transfer per meter radiator length as a function of spacing between two opposing convectors, b temperature distributions at different horizontal levels of $150 \mathrm{~mm}, 300 \mathrm{~mm}$ and $600 \mathrm{~mm}$

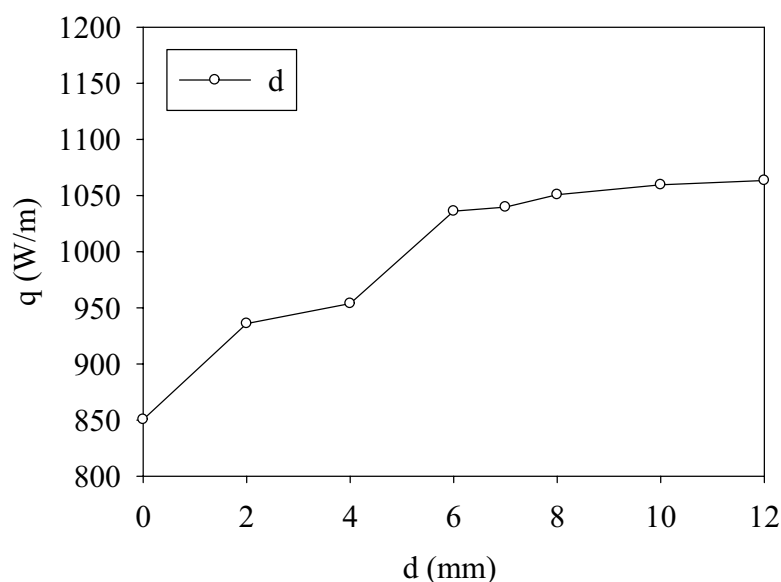

(a)

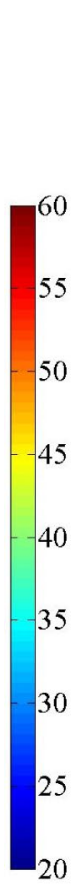

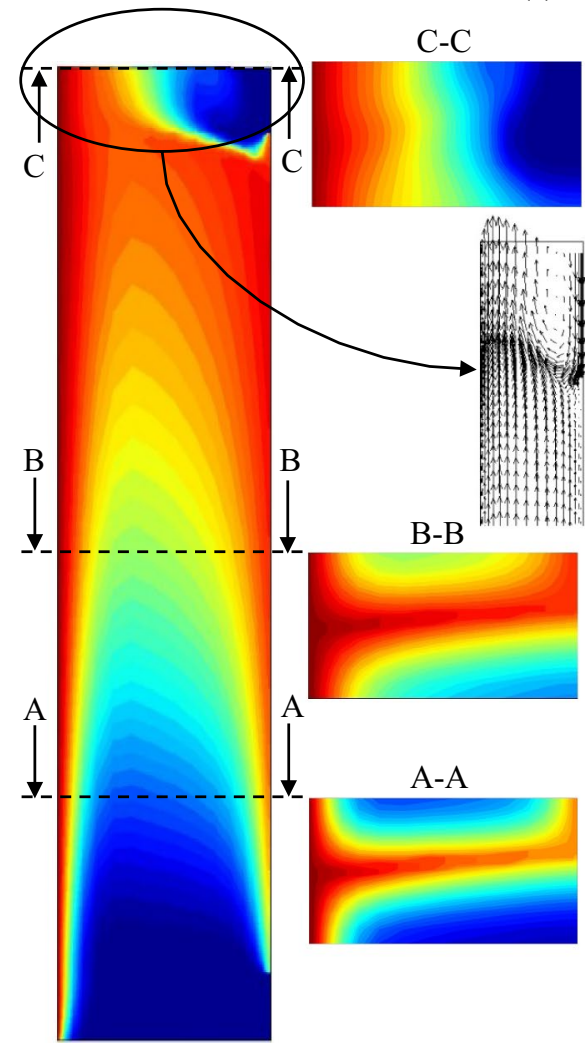

$\mathrm{d}=0 \mathrm{~mm}$

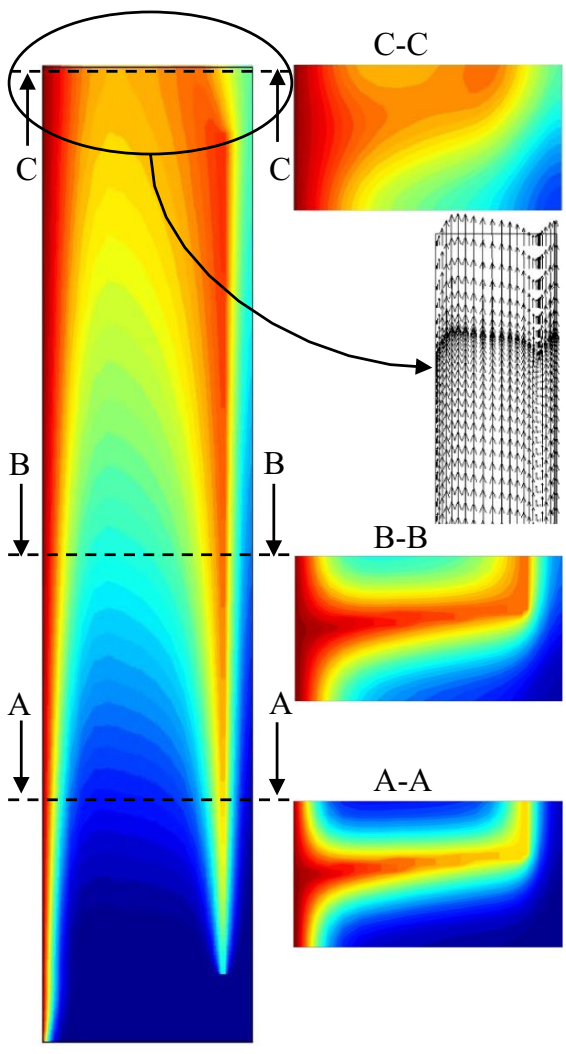

$\mathrm{d}=12 \mathrm{~mm}$

(b)

certain value of distance between opposite convectors the heat transfer is almost unaffected.

The tip width of the convectors has been investigated, and results are shown in Fig. 9. The increase in tip width increases the heat transfer. Figure $9 \mathrm{~b}$ shows that the tip width of $b=0 \mathrm{~mm}$ forms a triangular region confined by the convector. High temperatures occur inside this triangular region, and outside the convectors lower temperatures have been observed. Due to a low area, the flow is choked, and in addition, a low surface area occurs at the tip of the convector. This has a consequence on the overall heat transfer, hence the lowest heat transfer has been obtained for $b=0 \mathrm{~mm}$. Otherwise, the highest heat transfer is obtained for $b=12 \mathrm{~mm}$. Increase in tip width increases the surface area at the tip region of the convector. In addition, due to the increase in the area, inside the convector region the airflow is not choked, which has a positive effect on heat transfer.

The effect of vertical location of the convector for a convector height of $H=510 \mathrm{~mm}$ on heat transfer is 
Fig. 9 a Heat transfer per meter radiator length as a function of tip width of convectors, $\mathbf{b}$ temperature distributions at different horizontal levels of $150 \mathrm{~mm}, 300 \mathrm{~mm}$ and $450 \mathrm{~mm}$

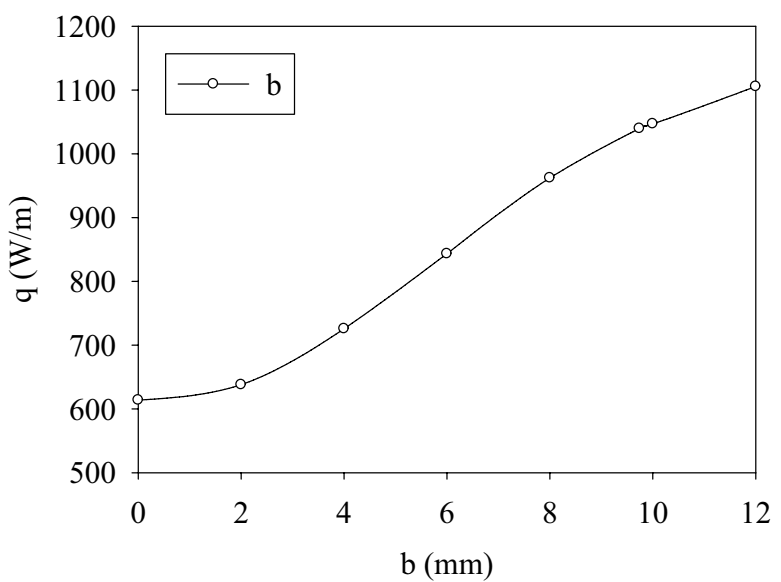

(a)
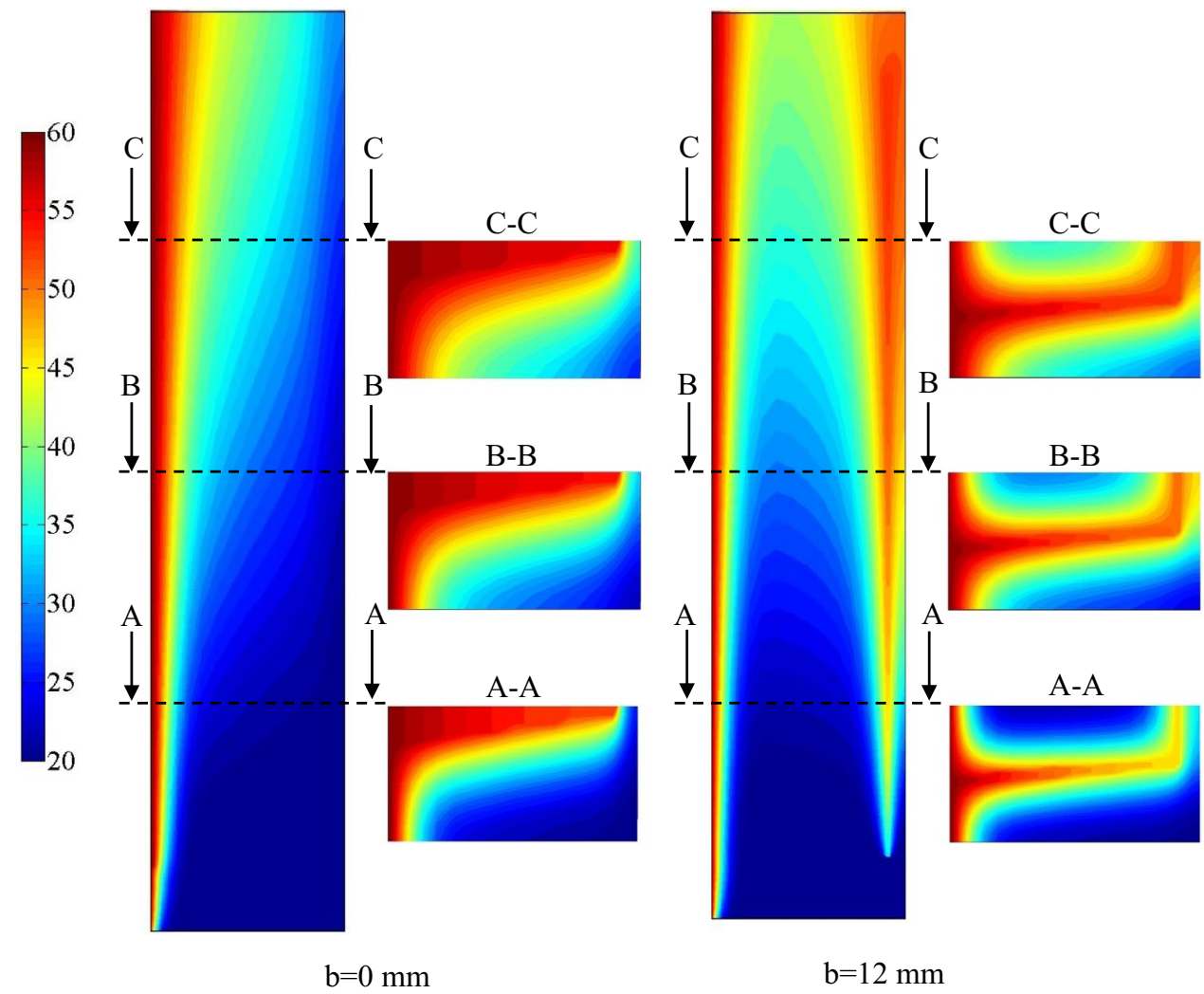

(b) presented in Fig. 10. The vertical temperature distribution along the height of the channel and the local temperature difference between the heated wall and air is shown in Fig. 10b. It was observed that the highest heat transfer can be obtained for the case of $f=0 \mathrm{~mm}$, where the convector is located at the lower outlet section $(z=0 \mathrm{~mm})$ of the vertical channel. The heat transfer decreases with the increase in vertical location. For $f=0 \mathrm{~mm}$ cold air, which enters the vertical channel, flows directly around the extended surfaces; hence, the increase in temperature difference in the mentioned area increases the heat transfer. Diversely for $f=90 \mathrm{~mm}$, a cold region occurs at the lower part of the channel, until the airflow reaches the convectors. Hence, a decrease in heat transfer occurs. At the vertical level of $z=0 \mathrm{~mm}$, a higher air temperature could be obtained for $f=0 \mathrm{~mm}$; hence, the temperature difference between the wall and air is lower compared to $f=90 \mathrm{~mm}$. This is the opposite for $z=600 \mathrm{~mm}$, where higher air temperatures occur for $f=90 \mathrm{~mm}$; these are the convectors which are close to 
Fig. 10 a Heat transfer per meter radiator length as a function of vertical convector location, $\mathbf{b}$ mean temperature distributions at different horizontal levels for $f=0 \mathrm{~mm}$ and $f=90 \mathrm{~mm}$ and temperature distributions on the $x-z$ plane

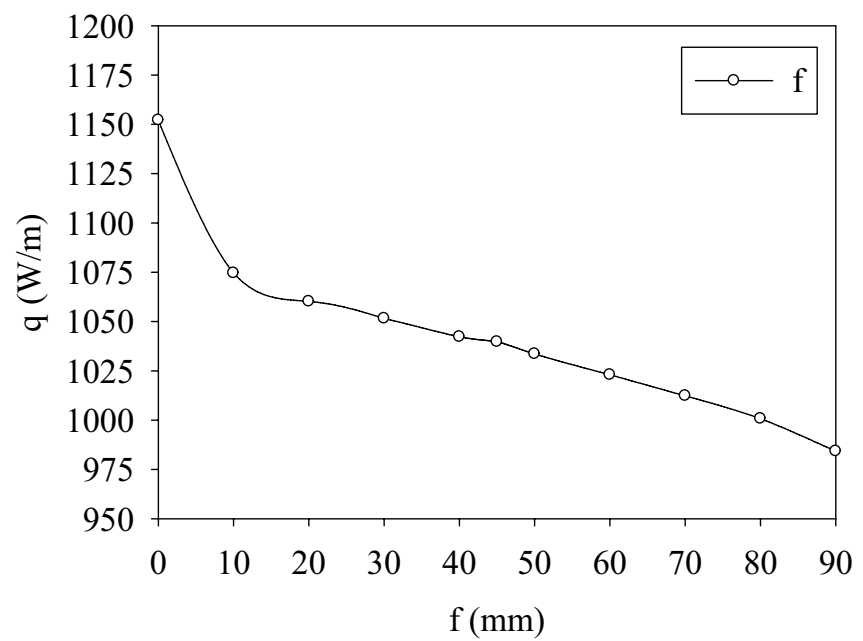

(a)

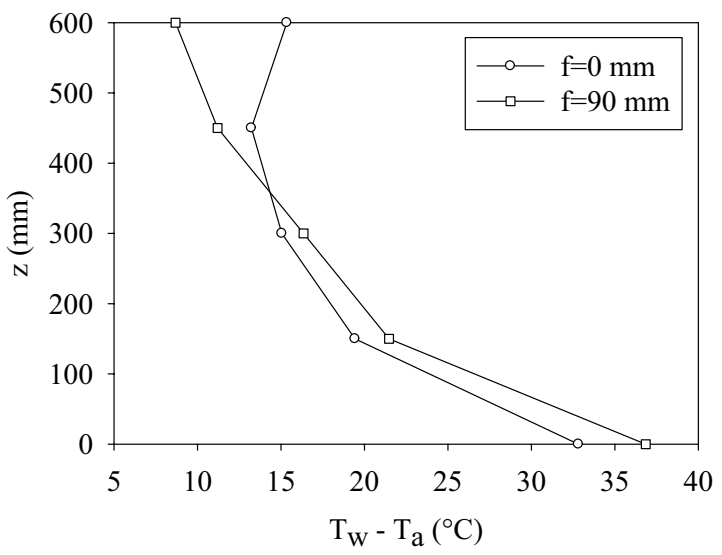

(b)
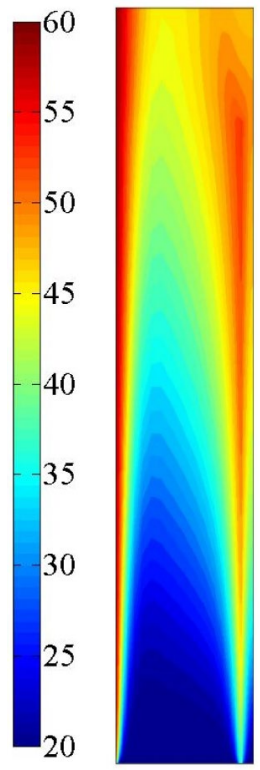

$\mathrm{f}=0 \mathrm{~mm}$

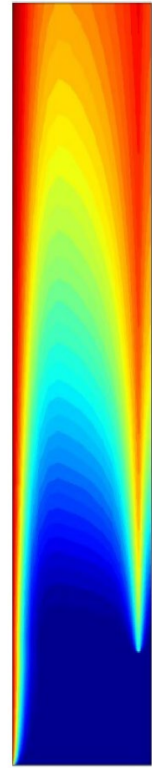

$\mathrm{f}=90 \mathrm{~mm}$ the upper outlet section. For both cases, the temperature decreases with increasing vertical heights.

The idea to create a mixing chamber between the convectors was suggested by Myhren and Holmberg [5], where they studied the effect of a mixing chamber for natural and forced convection of ventilation radiators convection fins. In the present study, a convector height of $H=510 \mathrm{~mm}$ was used, and percentage cut-off ratios were used at the mid-section of the convectors, to observe the effect of these mixing chambers on the heat transfer. The convection fins were interrupted at the mid-region to create a space, which formed a mixing chamber. This is the ratio of the distance of evacuated part to the total height of the fin. Using such a cut area of convection fins, it is possible to break the insulating thermal boundary layer, and in addition, it will be possible to use less material. The change in heat output with respect to cut-off ratios is shown in Fig. 11. The increase in cut-off ratio decreases the heat transfer, and the lowest heat transfer has been obtained for the case without convectors mounted on the heated wall. In Fig. 11b, break in the boundary layer was observed; however, for natural convection conditions the decrease in the surface area of the convectors has a major effect on heat transfer and accordingly temperature distributions. Therefore, with the increase in cut-off ratio the heat transfer as well as temperature values occurring inside the vertical channel decrease. The left figure in Fig. $11 \mathrm{~b}$ shows that the temperature difference for the case without convection fin is highest. This is due to the air, which is only in contact with the heated air, and outside 

meter radiator length as a function of cut-off ratio of convectors, $\mathbf{b}$ temperature difference between wall and air along channel height and temperature contours on the $x-z$ plane
Fig. 11 a Heat transfer per

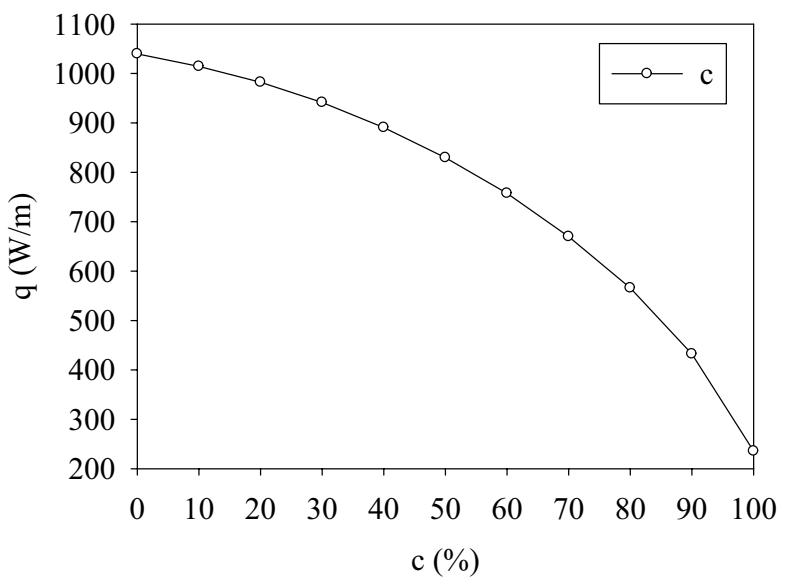

(a)
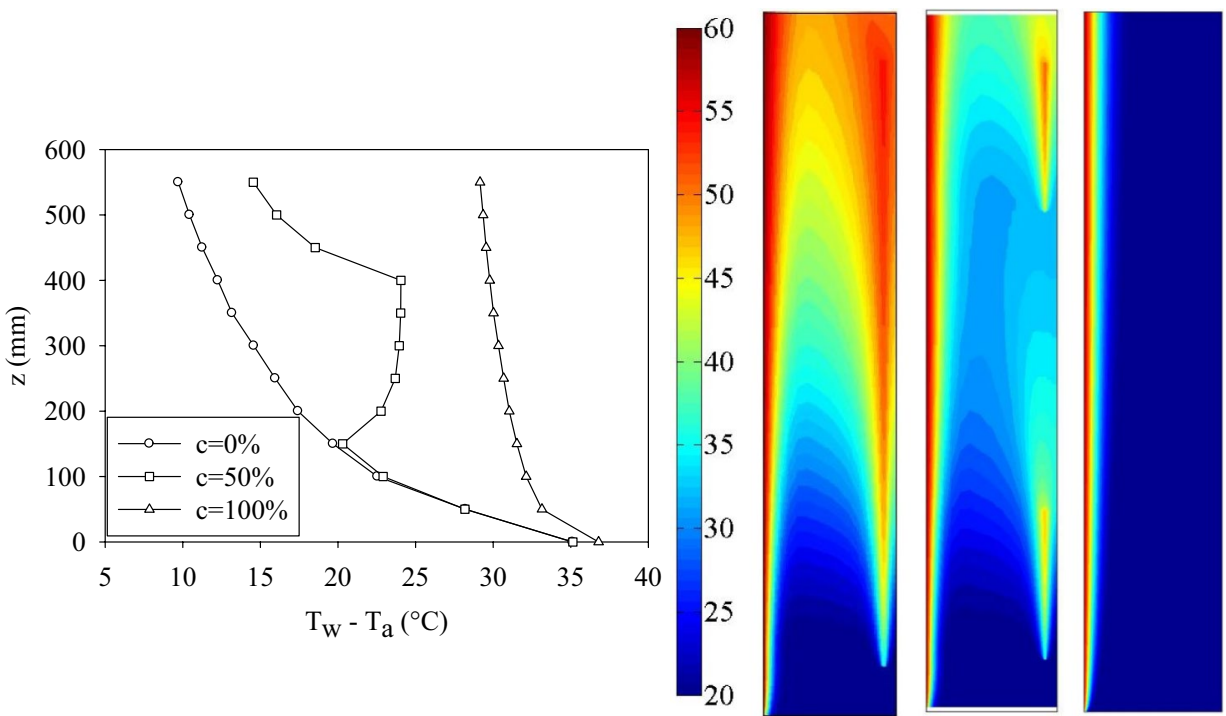

$\mathrm{c}=\% 0$

$\mathrm{c}=\% 50$ $\mathrm{c}=\% 100$

(b)

the boundary layer, the temperature remains as $20^{\circ} \mathrm{C}$. On the other hand, for the case of $c=50 \%$ and $c=0 \%$, the temperature difference between the wall and air are almost the same for $0 \leq z \leq 200 \mathrm{~mm}$. For $z>200 \mathrm{~mm}$ cold air entrainment occurs for $c=50 \%$ and the temperature difference increases, whereas for $c=0 \%$ the air temperature continues to increase and temperature difference decreases.

For the heat transfer inside the channel, a correlation has been derived by using the obtained simulation results. The least squares regression method has been employed to obtain the power exponents of the coefficients. The predicted versus the obtained heat transfer results are shown in Fig. 12. The correlation obtained from the numerical results has been presented in Eq. (13). The predicted results were within a range of $\pm 5 \%$, and a $95 \%$ confidence interval has been used to express the reliability of the power exponents [20].

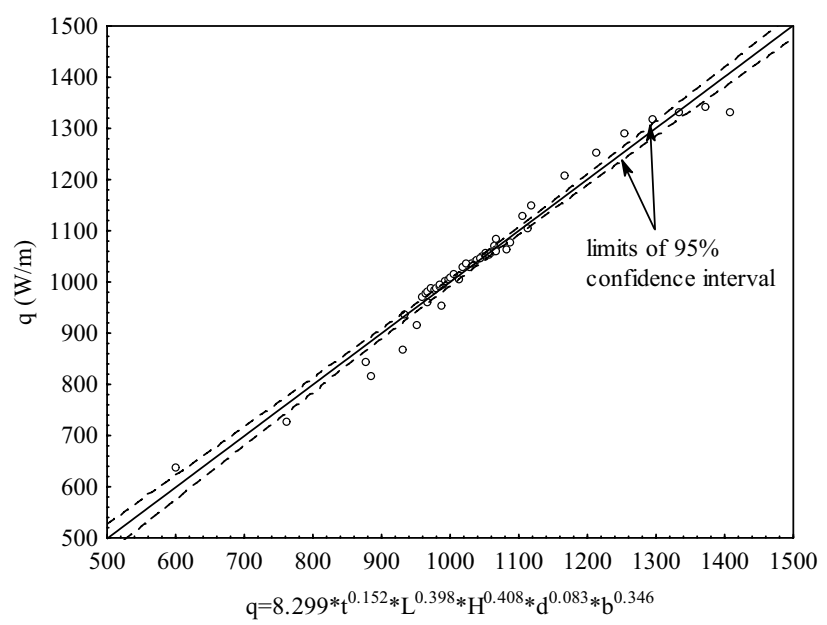

Fig. 12 Correlation results for the investigated parameters 
$q=A \times\left(t^{0.152}\right) \times\left(L^{0.398}\right) \times\left(H^{0.408}\right) \times\left(d^{0.083}\right) \times\left(b^{0.346}\right)$

$A=8.299 \mathrm{~W} / \mathrm{m} \mathrm{mm}^{1.387} ; 0.25 \mathrm{~mm} \leq t \leq 0.60 \mathrm{~mm} ; 25 \mathrm{~mm} \leq L \leq 80 \mathrm{~mm}$;

$450 \mathrm{~mm} \leq H \leq 600 \mathrm{~mm} ; 2 \mathrm{~mm} \leq d \leq 12 \mathrm{~mm} ; 2 \mathrm{~mm} \leq b \leq 12 \mathrm{~mm}$

The obtained correlation will be helpful to manufacturers in the more efficient design of new panel radiators.

\section{Conclusions}

A comprehensive numerical parametric study was performed to show the effects of different convector dimensions on the heat transfer and temperature distributions of panel radiators. The most important conclusions depicted from the findings are presented below.

- The increase in convector thickness increases the heat transfer almost linearly. However, although an increase of convector thickness from $t=0.25 \mathrm{~mm}$ to $t=0.60 \mathrm{~mm}$ increases the heat transfer at a rate of $18.8 \%$, the material mass increases at a rate of $58.3 \%$.

- Similar increase in heat transfer has been obtained for the change in convector height. The heat transfer could be increased by $8 \%$, with the increase of convector height from $H=450 \mathrm{~mm}$ to $H=600 \mathrm{~mm}$, whereas the use in the total amount of material was increased by almost $18 \%$.

- Heat transfer increases with the trapezoidal height and reaches a maximum at $L=75 \mathrm{~mm}$. The heat transfer increase rate degrades with the increase in convector trapezoidal height.

- Increase in the distance between opposing convectors increases the heat transfer and becomes almost constant for a distance of $d \geq 6 \mathrm{~mm}$.

- An increase of the heat transfer area occurs due to the increase in tip width, which augments the heat transfer. The cut section of the air flow is increased with the tip width; hence, an additional improvement in heat transfer is obtained. Whereas, due to blockage effects in the triangular confined region, this was not observed for a tip width of $b=0 \mathrm{~mm}$, which decreases the heat transfer.

- Due to the highest temperature difference occurring at the lower part of the channel, an increase in the surface area increases the heat transfer, hence the highest heat transfer has been obtained for the case of $f=0 \mathrm{~mm}$, where the convector is located at the lower inlet section of the vertical channel.

- Cutting off the mid-section of the convectors at different rates showed a decrease in heat transfer, and the highest heat transfer has been obtained for a convector without any extraction.

Acknowledgements Ministry of Science, Industry and Technology of Turkey (Grant No. 0641.STZ.2014) for financial support, and DemirDöküm A.Ş. are thankfully acknowledged.

\section{Compliance with ethical standards}

Conflict of interest On behalf of all the authors, the corresponding author states that there is no conflict of interest.

Open Access This article is licensed under a Creative Commons Attribution 4.0 International License, which permits use, sharing, adaptation, distribution and reproduction in any medium or format, as long as you give appropriate credit to the original author(s) and the source, provide a link to the Creative Commons licence, and indicate if changes were made. The images or other third party material in this article are included in the article's Creative Commons licence, unless indicated otherwise in a credit line to the material. If material is not included in the article's Creative Commons licence and your intended use is not permitted by statutory regulation or exceeds the permitted use, you will need to obtain permission directly from the copyright holder. To view a copy of this licence, visit http://creativecommons .org/licenses/by/4.0/.

\section{References}

1. Sarbu I, Sebarchievici C (2015) A study of the performance of low-temperature heating systems. Energy Effic 8:609-627

2. Arslanturk C, Ozguc AF (2006) Optimization of a central-heating radiator. Appl Energy 83:1190-1197

3. Beck SMB, Grinsted SC, Blakey SG, Worden K (2004) A novel design for panel radiators. Appl Therm Eng 24:1291-1300

4. Calisir T, Yazar HO, Baskaya S (2017) Determination of the effects of different inlet-outlet locations and temperatures on PCCP panel radiator heat transfer and fluid flow characteristics. Int J Therm Sci 121:322-335

5. Myhren JA, Holmberg S (2011) Improving the thermal performance of ventilation radiators - the role of internal convection fins. Int J Therm Sci 50:115-123

6. Myhren JA, Holmberg S (2013) Performance evaluation of ventilation radiators. Appl Therm Eng 51:315-324

7. Myhren JA, Holmberg S (2009) Design considerations with ventilation-radiators: comparisons to traditional two-panel radiators. Energy Build 41:92-100

8. Mundt E, Gustavsson M, Leksell P (1999) Vent-convector-an experimental study. In: Proceedings of Indoor Air 99, the 8th international conference on indoor air quality and climate, UK, vol 5

9. Yedikardeş Y, Teke I (2017) Effect of louvres on the thermal efficiency of panel radiators. Int Commun Heat Mass Transf 88:160-170

10. Arslanturk C (2006) Optimum design of space radiators with temperature-dependent thermal conductivity. Appl Therm Eng 26:1149-1157

11. Bagheri N, Moosavi A, Shafii MB (2020) Thermal enhancement of baseboard heaters using novel fin-tube arrays: experiment and simulation. Int J Therm Sci 151:106285 
12. Tran N, Wang CC (2020) Optimization of the airside thermal performance of mini-channel-flat-tube radiators by using composite straight-and-louvered fins. Int J Heat Mass Transf 160:120163

13. Ploskic A, Wang Q, Sadrizadeh S (2019) A holistic performance evaluation of ventilation radiators-an assessment according to EN 442-2 using numerical simulations. J Build Eng 25:100818

14. Gheibi A, Rahmati AR (2019) An experimental and numerical investigation on thermal performance of a new modified baseboard radiator. Appl Therm Eng 163:114324

15. Prek M, Krese G (2018) Experimental analysis of an improved regulation concept for multi-panel heating radiators: proof-ofconcept. Energy 161:52-59

16. Calisir T (2017) Numerical and experimental investigation of water channel, panel and convector separately and all together to enhance thermal output of Panel Radiator. PhD thesis, Gazi University
17. Cengel YA (2003) Heat transfer: a practical approach, 2nd edn. McGraw-Hill, New York

18. Elenbaas W (1942) Heat dissipation of parallel plates by free convection. Physica 9(1):1-28

19. Bar-Cohen A, Rohsenow WM (1984) Thermally optimum spacing of vertical natural convection cooled, parallel plates. J Heat Transf 106:116-123

20. Taler D (2018) Mathematical modeling and experimental study of heat transfer in a low-duty air-cooled heat exchanger. Energy Convers Manag 159:232-243

Publisher's Note Springer Nature remains neutral with regard to jurisdictional claims in published maps and institutional affiliations. 